\title{
PICTURES IN DIGESTIVE PATHOLOGY
}

\section{Appendicular mucocele as cause of chronic abdominal pain}

Sara López-García, Jorge Pérez-Grobas, María Berdeal-Díaz and Carlos Gómez-Freijoso

Complejo Hospitalario Universitario de A Coruña. Spain

\section{CASE REPORT}

We report the case of a 67 -years-old male who presents colic abdominal pain located in the right lower quadrant for over 2 years. No more symptoms.

Barium enema showed a large filling defect (narrow) in the medial wall of the cecum and this was thought to be the result of extrinsic compression by an appendiceal mass (Fig. 1).

At colonoscopy, deep in the cecum, through the appendiceal orifice, a protruding smooth submucosal lesion suggesting mucocele was observed (Fig. 2).

The surgery confirms the colonoscopy and barium enema findings and the patient underwent partial cecum resection and extirpation of the mucocele.

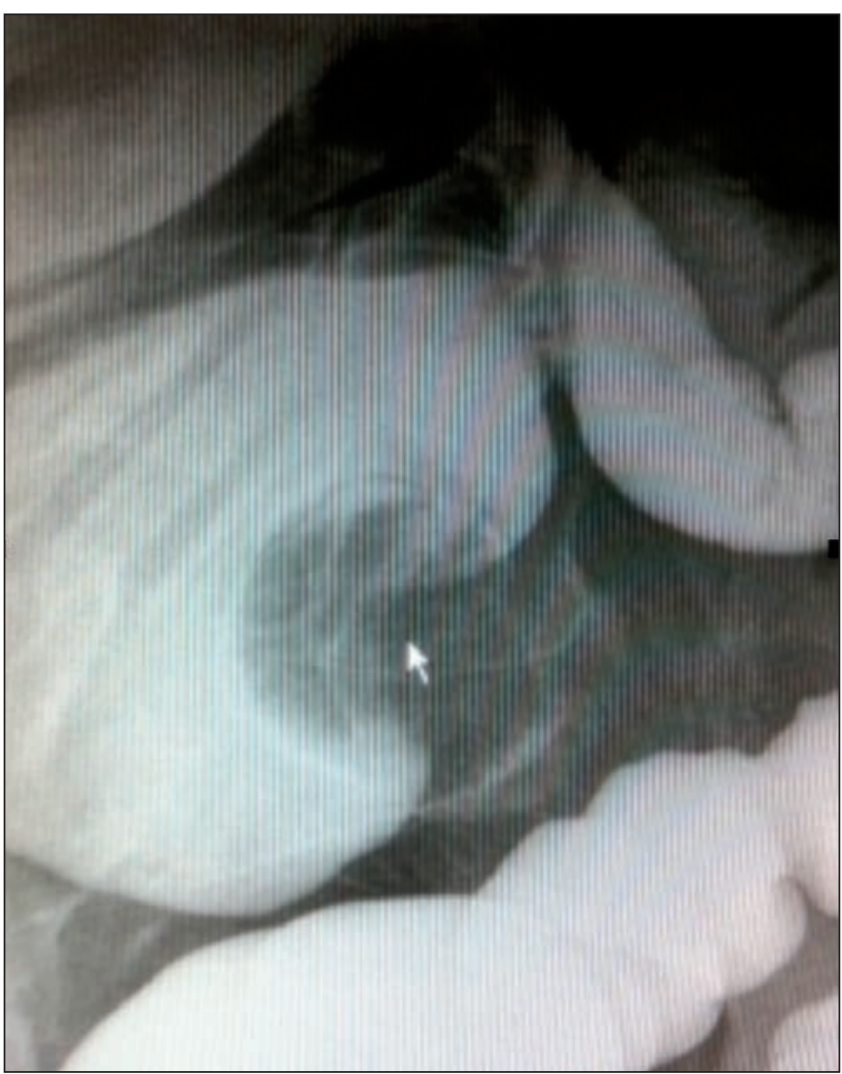

Fig. 1. Barium enema: large filling defect.

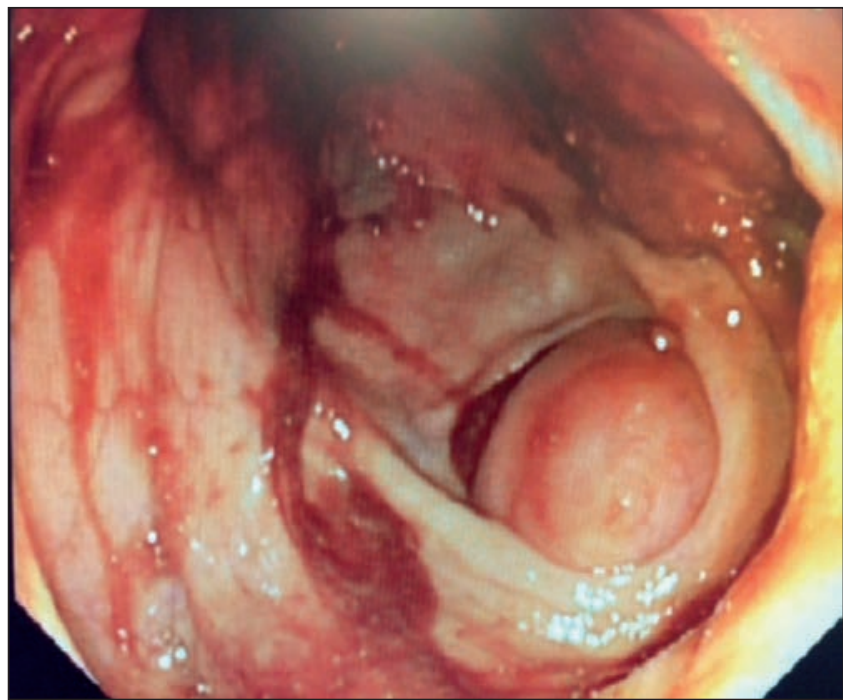

Fig. 2. Colonoscopy: smooth submucosal lesion. 


\section{DISCUSSION}

The histological analysis of the surgical specimen, revealed a cystic appendicular dilatation, which lumen was distended by mucin. Its surface was partially covered with a layer of mucinous columnar cells.

Appendicular mucocele is a rare lesion defined as a cystic dilatation of the appendiceal lumen by mucin accumulation. This is a rare lesion.

The histological analysis of the appendicular mucocele may recognize four different entities: mucous retention cyst, mucous hyperplasia, cystadenoma or cystadenocarcinom.

The differential diagnosis, include others appendicular tumors: carcinoid tumors, appendicular adenocarcinomas, and inflammations of the appendix (appendicitis and appendicular plastron).

\section{REFERENCES RECOMMENDED}

1. Utrillas Martínez AC, Muniesa Soriano JA, del Val Gil JM, Cruces Conde A, López Peris P, González Penabad M, et al. Appendicular mucocele. Rev Esp Enferm Dig 2008;100(11):736-7.

2. García Lozano A, Vázquez Tarrago A, Castro García C, Richart Aznar J, Gómez Abril S, Martínez Abad M. Mucocele apendicular: presentación de 31 casos. Cir Esp 2010;87(2):108-12.

3. Ruiz-Tovar J, Teruel DG, Castiñeiras VM, Dehesa AS, Quindos PL, Molina EM. Mucocele of appendix. World J Surg 2007;31:542 